\title{
Rapid and Efficient Synthesis of $\omega$-Alkylenediphosphoric Acids from Phosphorus Oxychloride
}

\author{
Dalila Meziane, ${ }^{1}$ Abdelhamid Elias, ${ }^{1}$ and Erwann Guénin ${ }^{2}$ \\ ${ }^{1}$ Département de Chimie, Faculté des Sciences, Université Mouloud Mammeri, BP 17 RP, 15000 Tizi Ouzou, Algeria \\ ${ }^{2}$ UFR SMBH, Université Paris 13, Sorbonne Paris Cité, 74 rue Marcel Cachin, 93017 Bobigny, France
}

Correspondence should be addressed to Erwann Guénin; guenin@univ-paris13.fr

Received 2 November 2015; Revised 16 December 2015; Accepted 11 January 2016

Academic Editor: Marijan Kocevar

Copyright (C) 2016 Dalila Meziane et al. This is an open access article distributed under the Creative Commons Attribution License, which permits unrestricted use, distribution, and reproduction in any medium, provided the original work is properly cited.

\begin{abstract}
The aim of this investigation was to develop an efficient, rapid, and selective method for the synthesis of $\omega$-alkylenediphosphoric acids $(\mathrm{HO})_{2}(\mathrm{O}) \mathrm{P}-\mathrm{O}-\left(\mathrm{CH}_{2}\right)_{n}-\mathrm{O}-\mathrm{P}(\mathrm{O})(\mathrm{OH})_{2}$ from reaction of several diols with phosphorus oxychloride. The reaction was investigated using three methodologies: (i) presence of a base, (ii) classical heating, and (iii) use of microwave irradiation. Influence of reaction temperature and molar ratio of reagents, as well as the nature of the solvent, was studied using these three different methods.
\end{abstract}

\section{Introduction}

Alkylphosphates, also called phosphate esters, have found numerous applications over the years mainly in various industrial processes, such as flame retardants, plasticizing agents, lubricants, surfactants, reagents in solvent extraction of heavy metal ions, and corrosion inhibitors [1-9].

Organic phosphates are generally synthesized from condensation of alcohol with several phosphorus substances: $\mathrm{P}_{2} \mathrm{O}_{5}, \mathrm{POCl}_{3}, \mathrm{PCl}_{3}, \mathrm{PCl}_{5}$, and $\mathrm{H}_{3} \mathrm{PO}_{4}$ [10-14]. In general, the products are mixtures of mono-, di-, and triesters, together with some byproducts and unreacted alcohols [15]. This phenomenon is of course enhanced when reacting diols or polyols. Nevertheless, selective formation of monoesters could be obtained by reacting excess of the phosphorus species, but this involves more difficult purification steps.

Among the different phosphorus reactants, phosphorus oxychloride appears as a good compromise to obtain monoalkylphosphates as it is less reactive than phosphorus chlorides. The synthesis of alkylphosphoric acids through the reaction of phosphorus oxychloride with alcohols involves two steps. The first step consists in a nucleophilic attack of the alcohol at the $\mathrm{P}$ center of $\mathrm{POCl}_{3}$, in order to yield the formation of an intermediate compound: phosphorodichloridate by a bimolecular mechanism (termed $\mathrm{SN}_{2} \mathrm{P}$ ) [16]. The second step is the hydrolysis of the phosphorodichloridate formed in the first step. By a similar way, the reaction of diols with $\mathrm{POCl}_{3}$ may be represented as shown in Scheme 1. By the same mechanism, two molecules of $\mathrm{POCl}_{3}$ may react with the same molecule of diol to form diphosphorotetrachloridate, which is then hydrolyzed in a second step, thus forming the desired alkylenediphosphoric acids: $(\mathrm{HO})_{2}(\mathrm{O}) \mathrm{P}-\mathrm{O}-\left(\mathrm{CH}_{2}\right)_{n}-\mathrm{O}-\mathrm{P}(\mathrm{O})-$ $(\mathrm{OH})_{2}$.

In fact, the reaction of a diol (as in case of an alcohol) with phosphorus oxychloride leads to a complex mixture of mono(di)alkylphosphoric acids, trialkylphosphate, and polyphosphoric acids. The proportion of each compound depends on the reaction conditions [17]. The lack of selectivity is a major inconvenience for this synthetic route, since the composition is hardly controlled giving generally low yields of the desired product which is difficult to separate from the crude mixture. Another problem of this reaction, mainly in case of alcohols or diols with long hydrocarbon chains, is their lower reactivity compared to the alcohols with shorter alkyl chain. At classical conditions, this low reactivity induces the need of long reaction times and high temperatures $\left(>100^{\circ} \mathrm{C}\right)$ $[11,18]$.

In this paper, we report reactions of phosphorus oxychloride with several diols with varying hydrocarbon chain length. In order to try to control the selectivity of the reaction, 


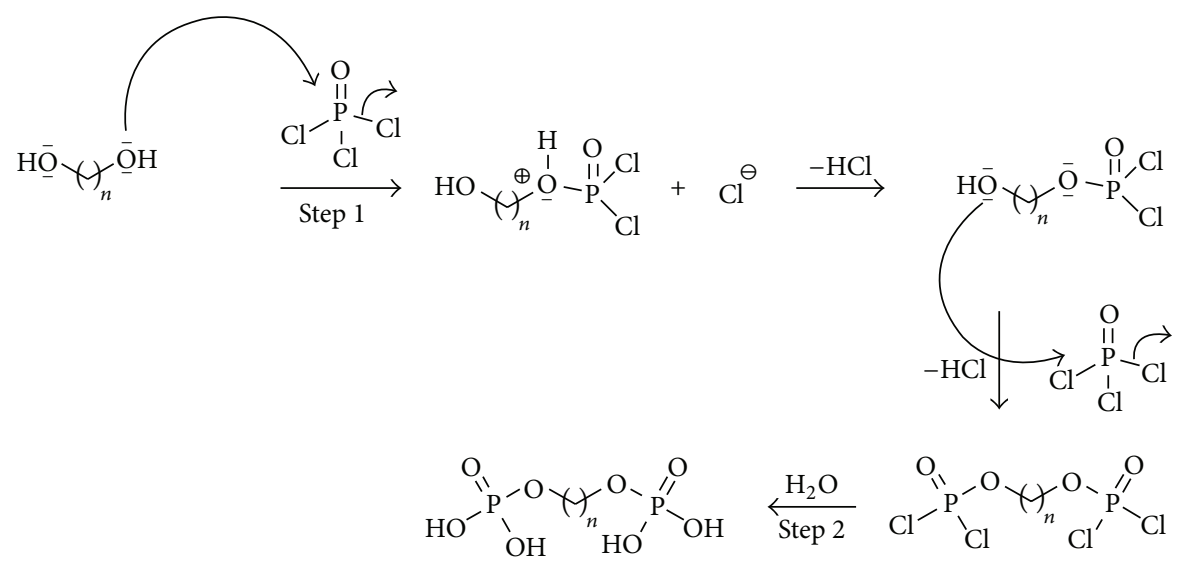

Example of possible byproducts<smiles>O=P(O)(OO)O[Te]O</smiles>

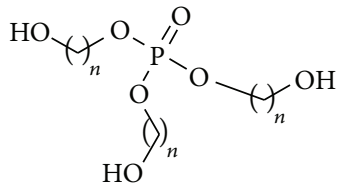<smiles>CC(C)OC(=O)OP(=O)(O)O[Te]OP(=O)(O)OC(C)(C)C</smiles>

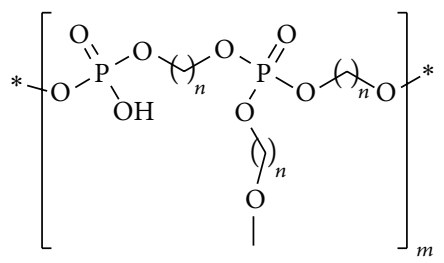

SCHeme 1: General route for the formation of $\omega$-alkylenediphosphoric acids from phosphorus oxychloride.

to obtain monoalkyl diphosphoric esters, and improve the synthetic process, we investigated three different approaches for this reaction: firstly the reactions were activated by classical heating and then by the use of triethylamine at low temperature and finally the reactions were run under microwave irradiation.

\section{Results and Discussion}

2.1. Method 1: Conventional Thermal Activation. Using conventional heating, the reactions were carried out according to a slightly modified procedure with respect to the one reported for similar products [18]. A large excess of $\mathrm{POCl}_{3}$ versus diol was used $(R=4)$ and refluxed with the diol for several hours in toluene. The evolution of the reaction was followed by NMR; the ${ }^{31} \mathrm{P}\left\{{ }^{1} \mathrm{H}\right\}$ spectrum showed the appearance of a new peak around 5-6 ppm which corresponds to the monoalkyl phosphorodichloridate intermediates $\left(\mathrm{POCl}_{3}\right.$ signal appears around $4.5 \mathrm{ppm}$ (Figure 1(a))). During the hydrolysis step, we noted some progressive decrease of the peak area, at $6 \mathrm{ppm}$, in favor of a new one, around $0 \mathrm{ppm}$, corresponding to the desired products. The other peaks, observed with a little contribution, correspond to byproducts due to a partial hydrolysis of $\mathrm{POCl}_{3}$ and formation of anhydride (Figure 1(b)). The desired product was then isolated by means of precipitation from methanol/ethyl acetate $(1 / 4)$. The final product corresponds to the monoesterified phosphoric acids. However, it is worth mentioning that under whatever conditions used it was never obtained in pure form. The maximum purity (calculated by ${ }^{31} \mathrm{P}$ NMR) that corresponds to optimized conditions was $95 \%$. The remaining $5 \%$ impurities were attributed to the formation of at least one dialkyl phosphoric acid. Attempts to realize the reaction with a decreased or stoechiometric ratio of $\mathrm{POCl}_{3} / \mathrm{Diol}(R=2$ or $R=3$ ) were unsuccessful; it resulted in product mixtures only, which were quite difficult to separate or even to identify. Using the optimized conditions, pure products were obtained, yields ranging from $65 \%$ to $85 \%$, depending on the diols nature (Table 1). Although appreciable yields and purity are obtained, this method presents some drawback, such as length of reaction (several hours) and need of high reaction temperatures and excess of $\mathrm{POCl}_{3}$.

2.2. Method 2: Activation by a Base (NEt 3 ). Due to the low nucleophilicity of diols their reaction with $\mathrm{POCl}_{3}$ is slow. In the literature, bases are frequently used to activate the reaction of hydroxyl compounds with phosphorus oxychloride [17]. In this study, we tested the activating role of triethylamine $\left(\mathrm{NEt}_{3}\right)$ in the reaction of diols with $\mathrm{POCl}_{3}$. $\mathrm{NEt}_{3}$ has a double character: nucleophilic and basic, so it can readily react with $\mathrm{POCl}_{3}$ to form an activated product 


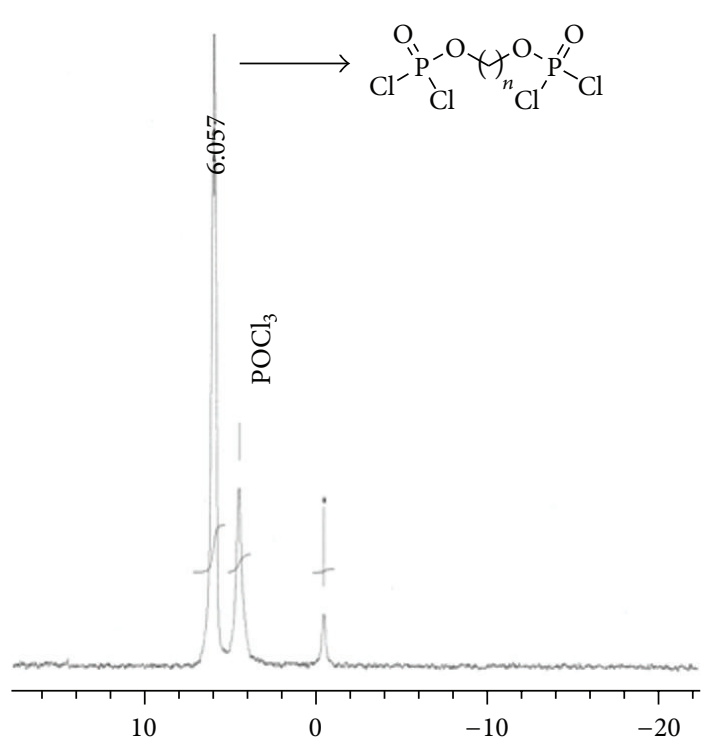

(a)

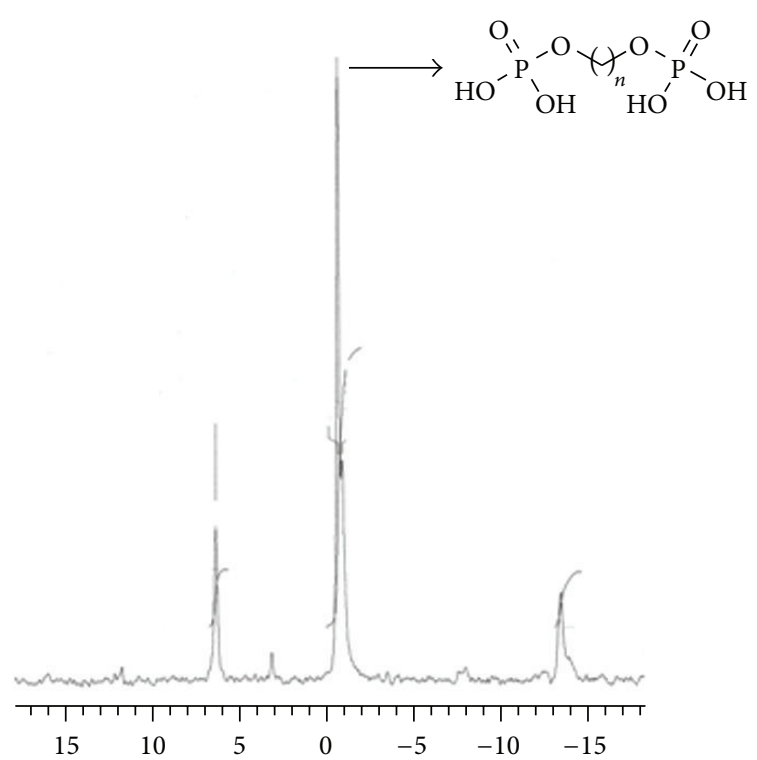

(b)

FIGURE $1:{ }^{31} \mathrm{P}$ NMR spectra of the reaction mixtures, obtained during the two-step synthesis. (a) Step 1, (b) step 2 (Method 1).

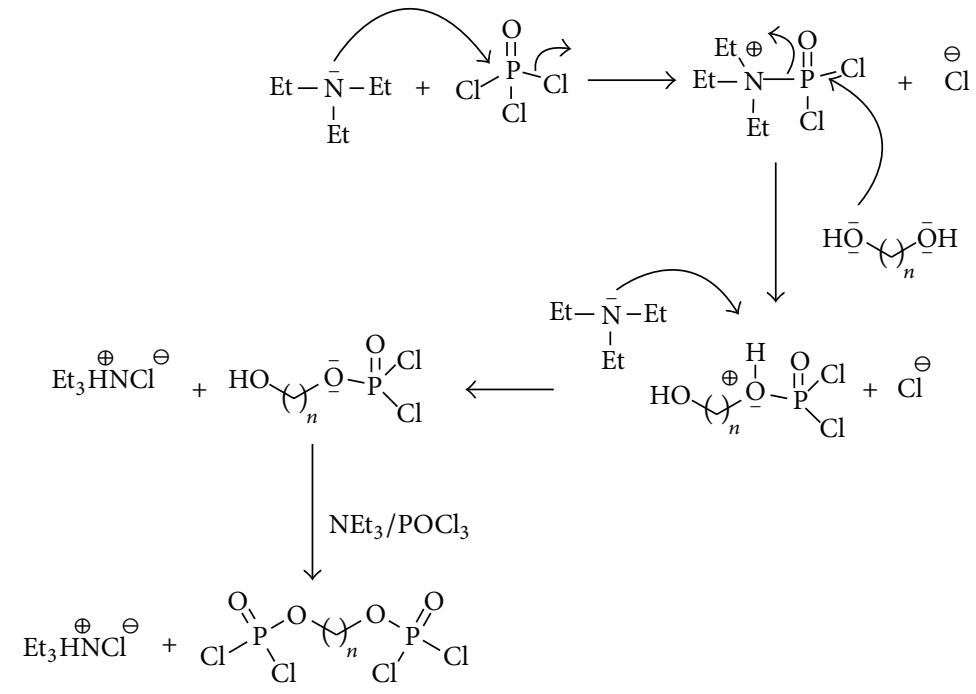

Scheme 2: General route to the formation of $\omega$-alkylenediphosphoric acids from phosphorus oxychloride, using triethylamine.

(Scheme 2). This positively charged intermediate is more reactive than the $\mathrm{POCl}_{3}$. It is then easily attacked by the hydroxyl group of the diols. The reaction is even exothermic and was conducted at low temperature $\left(-15^{\circ} \mathrm{C}\right)$, implying some handling caution. In this reaction, the amine plays a second role which consists in the fixation of the formed $\mathrm{HCl}$ and provides the corresponding chlorhydrate $\left(\mathrm{NEt}_{3}, \mathrm{HCl}\right)$. The precipitation of the chlorhydrate, in an adequate solvent, displaces the reaction-equilibrium towards the formation of the phosphonic ester (Scheme 2).

The reactions of $\mathrm{POCl}_{3}$ with diols, according to this pathway, were followed by NMR. The ${ }^{31} \mathrm{P}\left\{{ }^{1} \mathrm{H}\right\}$ NMR spectra showed the formation of different intermediates, but at the end of the process, the major product showed a signal around 5-6 ppm (Figure 2(a)). After a hydrolysis step, these intermediates mainly afford the desired product and other nonidentified byproducts, probably resulting from polyesterification. In this procedure, an excess of $\mathrm{POCl}_{3}$ was also necessary to lessen double or even triple attack of the diols, on the same $\mathrm{POCl}_{3}$ molecule, allowing for the formation of di- or trialkylphosphates compounds. Nevertheless use of 4 equivalents of $\mathrm{POCl}_{3}$ did not completely avoid the formation of these byproducts, since the desired product was never obtained in pure form (maximum purity obtained was 90\%). One must also note that an increase in $\mathrm{POCl}_{3}$ did not result in any increase of purity either. 
TABLE 1: Reaction conditions and results of the synthesized products with the different methods.

\begin{tabular}{lccc}
\hline & \multicolumn{3}{c}{ Yield $\eta(\%)$} \\
Diols $\rightarrow$ & $\mathbf{C}_{6}$ & $\mathbf{C}_{9}$ & $\mathbf{C}_{12}$ \\
\hline $\begin{array}{l}\text { Method } 1 \\
T=110^{\circ} \mathrm{C}, R=4, t_{r}=8-10 \mathrm{~h},\end{array}$ & $70^{\mathrm{a}}$ & $65^{\mathrm{a}}$ & $85^{\mathrm{a}}$ \\
solvent: toluene & & & \\
\hline $\begin{array}{l}\text { Method } 2 \\
T=-15^{\circ} \mathrm{C} \rightarrow 20^{\circ} \mathrm{C}, R=4, R^{\prime}=4,\end{array}$ & $65^{\mathrm{b}}$ & $62^{\mathrm{b}}$ & $75^{\mathrm{b}}$ \\
$t_{r}=2 \mathrm{~h}$, & & & \\
$\begin{array}{l}\text { solvents: THF }\left(\mathbf{C}_{12}\right) \text { or diethyl ether } \\
\left(\mathbf{C}_{6} \text { and } \mathbf{C}_{9}\right)\end{array}$ & & & \\
\hline $\begin{array}{l}\text { Method } 3 \\
T_{\text {Max }}=85^{\circ} \mathrm{C}, R=2, t_{r}=2 \text { min, } \\
W=100 \mathrm{~W}, \text { solvent: acetonitrile }\end{array}$ & 65 & 68 & 72 \\
\hline
\end{tabular}

$t_{r}$ : reaction time (step 1), $R$ : molar ratio $\mathrm{POCl}_{3} /$ diol, $R^{\prime}$ : molar ratio triethylamine/diol, $\mathbf{C}_{6}$ : hexane-1,6-diol, $\mathbf{C}_{9}$ : nonane-1,9-diol, and $\mathbf{C}_{12}$ : dodecane1,12-diol.

${ }^{a, b}$ Products were not obtained in pure form (maximum purity a: $95 \%$, b: $90 \%)$.

During the reaction, an excess of $\mathrm{NEt}_{3}$ was also needed in order to scavenge the totality of the formed $\mathrm{HCl}$ and thus avoid the formation of chloroalkanes as byproducts. Use of low molar ratios (2-3 equivalents) of $\mathrm{POCl}_{3}$ and/or $\mathrm{NEt}_{3}$ gave quite complex mixtures. Only small quantities of the desired product were formed and isolated in this case. Different solvents were evaluated for the reaction (dichloromethane, tetrahydrofuran, and diethyl ether). The best results were obtained with diethyl ether in case of $\mathbf{C}_{6}$ and $\mathbf{C}_{9}$ diols, while in case of $\mathbf{C}_{12}$ the best results were obtained with THF. The success of the reactions with these solvents is probably due to the precipitation of the chlorhydrate salt $\left(\mathrm{NEt}_{3}, \mathrm{HCl}\right)$. When dichloromethane, in which triethylammonium salt is known to be partially soluble, was used, only low quantity of product was extracted. Using the optimized conditions, yields lie in the range $62 \%-75 \%$. These are comparable to those obtained with the first method yet the products exhibit less purity (reaching its maximum at $90 \%$ ). However, this second method presents two advantages as compared to thermal activation: that is a decrease of the reaction time $(2 \mathrm{~h}$ versus $10 \mathrm{~h}$ ) and the absence of any heating, since everything works at ambient temperature, as compared to the usual $110^{\circ} \mathrm{C}$. The major inconvenience of this procedure lies in the need of reagents, $\mathrm{POCl}_{3}(R=4)$ and amine $\left(R^{\prime}=4\right)$, in excess.

2.3. Method 3: Activation by Microwave Irradiation. Microwave offers a number of advantages over conventional heating, such as fast-and-homogeneous noncontact heating [19]. Moreover, use of microwaves offers drastically reduced processing time. That could, in fact, account for its spreading during the last three decades, in several areas of chemistry [20]. In particular, this methodology had a positive impact on phosphorus chemistry as well as on several organophosphorus reactions that has benefited from the use of microwaves $[21,22]$. We thus apply it to the synthesis of $\omega$-alkylenediphosphoric acids. The reaction was conducted in open vessel by controlling power delivery during the reaction. Under microwave irradiation, the final and intermediate products emerging from the reaction of diols with $\mathrm{POCl}_{3}$ were identical to those which were formed using conventional heating. These products essentially consist in the diphosphorotetrachloridate formed in the first step (Scheme $2)$ and the alkylenediphosphoric acids $(\mathrm{HO})_{2}(\mathrm{O}) \mathrm{P}-\mathrm{O}\left(\mathrm{CH}_{2}\right)_{n}{ }^{-}$ $\mathrm{O}-\mathrm{P}(\mathrm{O})-(\mathrm{OH})_{2}$ obtained after the hydrolysis step (Figure 3).

The results are satisfactory (65-72\%) and comparable to those obtained with the previous methods (1 and 2) (Table 1). However, this time the purity was better as no traces of di- or polyalkylphosphate were observed. Another asset of this methodology was that the amount of phosphorus oxychloride was reduced by a factor 2 , from 4 to 2 equiv., and the reaction time of the diphosphorotetrachloridate formation was shortened to 2 minutes, instead of more than 8 hours when using thermal heating. This method, compared to method 2, has also the advantage of being catalystfree.

Polar solvents like acetonitrile seem to be useful for the reaction under microwave irradiation. When toluene was used, only traces of products are detected even under much harsher conditions $(P=150 \mathrm{~W}, t=30 \mathrm{~min}$, and $R=4$ ). This is due to the nonpolar nature of toluene, as only polar molecules selectively absorb microwaves while nonpolar molecules are known to be inert to microwave dielectric losses [20, 23]. Indeed, the heat generated by the reactants rotating molecules, when submitted to microwave irradiation, dissipated in this solvent through convection mechanisms. Using the conditions cited above, the resulting temperature $\left(T_{\max }=40^{\circ} \mathrm{C}\right)$ is too low to activate the reaction. Tests, carried out without solvent, generated a rapid and uncontrollable increase of the temperature in the reaction mixture, especially when no excess of $\mathrm{POCl}_{3}(R=2)$ was used. Yields in solvent-free conditions did not exceed $50 \%$, even under the use of a large excess of the reagent $(R=4)$.

The optimal conditions and the corresponding yields for the 3 methodologies are summarized in Table 1.

\section{Experimental Section}

3.1. Reagents and Solvents. Phosphorus oxychloride (99\%), triethylamine (>99\%), and diols hexane-1,6-diol (99\%), nonane-1,9-diol (98\%), and dodecane-1,12-diol (99\%) were purchased from Sigma-Aldrich. Diols were used without further purification. Phosphorus oxychloride and triethylamine were distilled before use. All solvents were purchased from Carlo Erba-SDS and also distilled before use. Dichloromethane, acetonitrile, and ethyl acetate were distilled over $\mathrm{P}_{2} \mathrm{O}_{5}$. Methanol, ethanol, diethyl ether, and toluene were distilled over sodium. The THF was likewise distilled over sodium in presence of benzophenone.

3.2. Instruments. NMR spectra were recorded with a VARIAN Unity Inova $500 \mathrm{MHz}\left({ }^{13} \mathrm{C}: 125.9,{ }^{1} \mathrm{H}: 500.6 \mathrm{MHz}\right)$ or a VARIAN Gemini $200 \mathrm{MHz}\left({ }^{31} \mathrm{P}: 80.9 \mathrm{MHz}\right)$ spectrometer in $\mathrm{CD}_{3} \mathrm{OD}$. Chemical shifts are reported in parts per million (ppm) on the $\delta$ scale. The residual solvent peak $\left(\mathrm{CD}_{3} \mathrm{OH}\right)$ was used as a reference for ${ }^{1} \mathrm{H}$ NMR $(3.31 \mathrm{ppm})$ and ${ }^{13} \mathrm{C}$ 


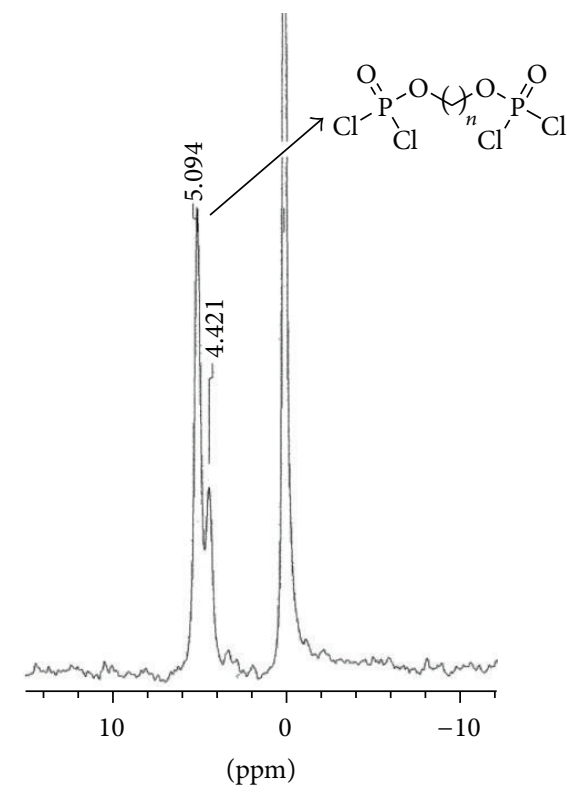

(a)

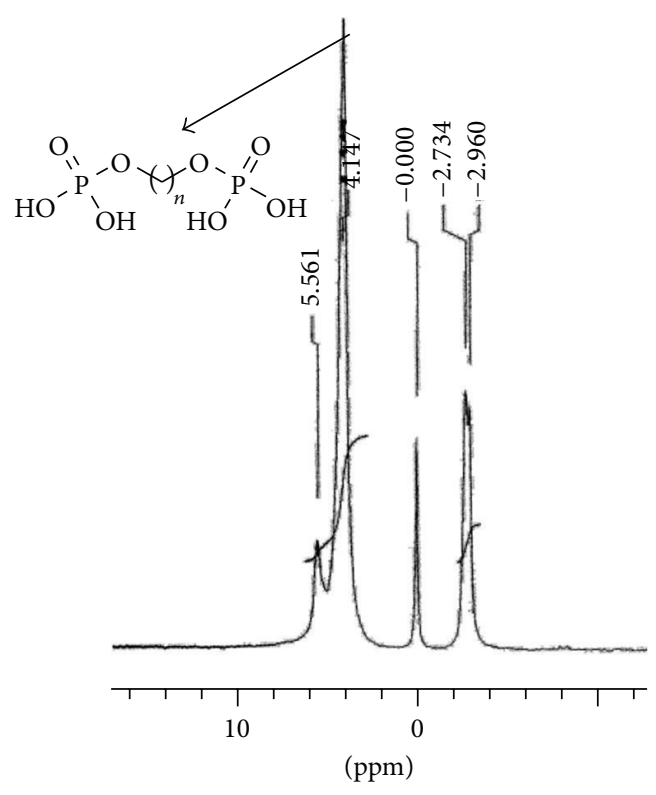

(b)

FIGURE 2: ${ }^{31} \mathrm{P}$ NMR spectra of the reaction mixtures obtained during the two-step synthesis. (a) Before the hydrolysis (step 1). (b) During hydrolysis step 2 (Method 2).

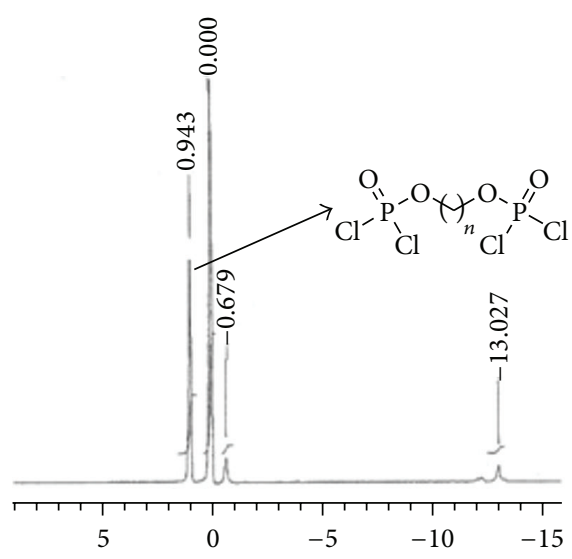

(a)

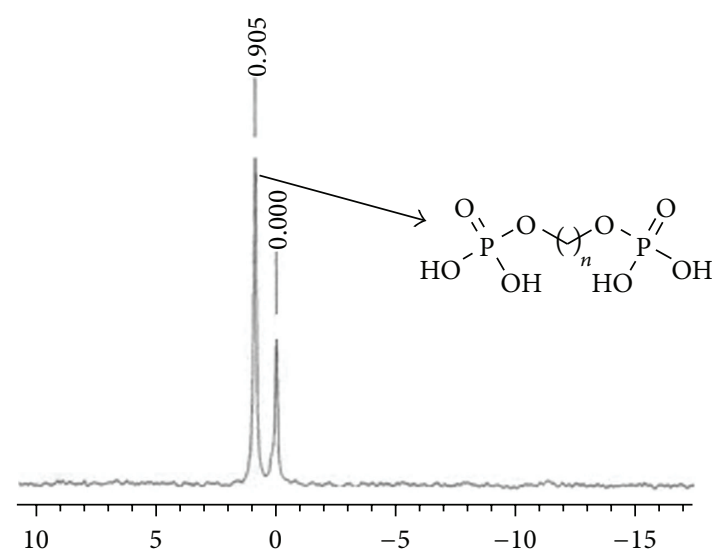

(b)

FIGURE 3: ${ }^{31} \mathrm{P}$ NMR spectra of 1,12-Bis[(dihydroxyphosphinyl)oxy]dodecane obtained with method 3. (a) Crude mixture obtained during step 1. (b) Crude mixture obtained after hydrolysis step 2 and before purification.

NMR (49.0 ppm). ${ }^{31} \mathrm{P}$ NMR spectra were recorded using phosphoric acid (85\%) as the external reference. Data are reported as follows: $\mathrm{s}=$ singlet, $\mathrm{d}=$ doublet, $\mathrm{t}=$ triplet, $\mathrm{q}=$ quartet, $\mathrm{dt}=$ doublet of triplet, and $\mathrm{m}=$ multiplet. Coupling constants are given in Hz. The FTIR spectra were recorded using a Nicolet FTIR 380 spectrophotometer and measured in wavenumbers $\left(\mathrm{cm}^{-1}\right)$. The mass spectra were run on a MALDI-TOF mass spectrometer (Biflex IV, Bruker Daltonique) with 2,5-dihydroxybenzoic acid as matrix.

All melting points are recorded using a Stuart SMP3 melting point apparatus and are uncorrected.

All experiments under microwave irradiations were run in open vessel, using a CEM-Discover microwave apparatus.
3.3. General Procedure for the Conventional Heating Synthesis (Method 1). The following procedure was adapted from synthesis reported for similar compounds [18]. Phosphorus oxychloride (30.66 g; $200 \mathrm{mmol})$ and the diol $(5.9 ; 8.01 ; 10.11 \mathrm{~g}$ (resp., for $n=6,9$, or 12 ); $50 \mathrm{mmol}$ ) were added under argon successively to a round bottom flask containing $120 \mathrm{~mL}$ of toluene. The mixture was refluxed for 8 to $10 \mathrm{~h}$ under magnetic stirring. The solution was then concentrated with a rotary evaporator and the viscous residue was coevaporated twice with $100 \mathrm{~mL}$ of toluene.

In the second step the obtained residue was hydrolyzed by $100 \mathrm{~mL}$ of cold water. Distilled water was added carefully to the residue, previously cooled $\left(5-10^{\circ} \mathrm{C}\right)$. Then the 
solution was warmed down to $90^{\circ} \mathrm{C}$ and stirred for 2 to 3 hours. During the hydrolysis, a white precipitate appeared and was isolated after water filtration. The obtained white solid was dissolved in $100 \mathrm{~mL}$ of ethanol which was then evaporated. This operation was repeated twice in order to remove the remaining $\mathrm{HCl}$. The residue was finally dissolved in methanol/ethyl acetate (1/4) (v/v) and the solution was left to precipitate overnight (in a freezer for compounds I and II, at r.t for compound III). The white powder was filtered, washed with diethyl ether, and dried in desiccators.

3.4. General Procedure for the Synthesis Using Triethylamine (Method 2). In a $150 \mathrm{~mL}$ tricol flask equipped with a reflux condenser, a thermometer, and an addition funnel a solution of phosphorus oxychloride $(9.2 \mathrm{~g} ; 60 \mathrm{mmol})$ was mixed with $30 \mathrm{~mL}$ of solvent (diethyl ether, dichloromethane, or tetrahydrofuran (THF)). A solution of diol $(15 \mathrm{mmol})$ and triethylamine ( $6.08 \mathrm{~g} ; 60 \mathrm{mmol})$ was then introduced dropwise. The reaction being very exothermic, the flask was placed in a mixture of liquid nitrogen and ethanol to keep the temperature at approximately $-15^{\circ} \mathrm{C}$, during the reagent addition. After completion of the addition, the mixture was stirred at room temperature $\left(20^{\circ} \mathrm{C}\right)$ for 2 hours. $20 \mathrm{~mL}$ of distilled water was then added to the reaction mixture and left under magnetic stirring, at room temperature, overnight. The mixture was then concentrated with a rotary evaporator before $20 \mathrm{~mL}$ of cold water was finally added to the viscous residue and the yellow organic layer removed from the aqueous phase. The desired product was isolated by recrystallization from methanol/ethyl acetate (1/4) (v/v).

3.5. General Procedure for the Synthesis under Microwave Irradiation (Method 3). Phosphorus oxychloride (3.36 g; $22 \mathrm{mmol}$ ) was placed in a $100 \mathrm{~mL}$ flask, equipped with a reflux condenser and closed by a calcium chloride tube with a diol $(10 \mathrm{mmol})$ and acetonitrile $(15 \mathrm{~mL})$ as solvent. The mixture was then irradiated at $100 \mathrm{~W}$ for $2 \mathrm{~min}$, under vigorous stirring. The mixture initially heterogeneous became homogenous within a few seconds of irradiation. At the end of the irradiation process, the mixture is poured into a flask containing $30 \mathrm{~mL}$ of cold distilled water. The hydrolysis and the purification procedures are similar to those described in method 1 .

3.6. (1,6-Bis[(dihydroxyphosphinyl)oxy]hexane) (Compound I). $\mathrm{mp}=96^{\circ} \mathrm{C} .{ }^{31} \mathrm{P}\left\{{ }^{1} \mathrm{H}\right\} \mathrm{NMR} \delta: 0.2 .{ }^{1} \mathrm{H} \mathrm{NMR} \delta: 3.97(\mathrm{dt}, 4 \mathrm{H}$, $\left.{ }^{3} J_{\mathrm{H}-\mathrm{H}}={ }^{3} J_{\mathrm{P}-\mathrm{H}}=6.5 \mathrm{~Hz}, \mathrm{POCH}_{2}\right) ; 1.68\left(\mathrm{~m}, 4 \mathrm{H}, \mathrm{POCH}_{2} \mathrm{CH}_{2}\right)$; $1.45\left(\mathrm{~m}, 4 \mathrm{H}, \mathrm{POCH}_{2} \mathrm{CH}_{2} \mathrm{CH}_{2}\right) .{ }^{13} \mathrm{C}\left\{{ }^{1} \mathrm{H}\right\} \mathrm{NMR} \delta: 67.7\left(\mathrm{~d},{ }^{2} J_{\mathrm{P}-\mathrm{C}}\right.$ $\left.=5.8 \mathrm{~Hz}, \mathrm{POCH}_{2}\right) ; 31.4\left(\mathrm{~d},{ }^{3} \mathrm{~J}_{\mathrm{P}-\mathrm{C}}=5.8 \mathrm{~Hz}, \mathrm{POCH}_{2} \mathbf{C H}_{2}\right) ; 26.3$ $\left(\mathrm{POCH}_{2} \mathrm{CH}_{2} \mathrm{CH}_{2}\right)$. Elementary Analysis $\mathrm{C}_{6} \mathrm{H}_{16} \mathrm{O}_{8} \mathrm{P}_{2}$ calcld C: 25.9; H: 5.8; O: 46.0; P: 22.3 found C: 26.2; H: 5.7; O: 46.4; P: 21.7 .

3.7. 1,9-Bis[(dihydroxyphosphinyl)oxy]nonane (Compound II). $\mathrm{mp}=109^{\circ} \mathrm{C} .{ }^{31} \mathrm{P}\left\{{ }^{1} \mathrm{H}\right\} \mathrm{NMR} \delta: 0.6 .{ }^{1} \mathrm{H}$ NMR $\delta: 3.96$ $\left(\mathrm{dt}, 4 \mathrm{H},{ }^{3} J_{\mathrm{H}-\mathrm{H}}={ }^{3} J_{\mathrm{P}-\mathrm{H}}=6.7 \mathrm{~Hz}, \mathrm{POCH}_{2}\right) ; 1.67(\mathrm{~m}, 4 \mathrm{H}$, $\left.\mathrm{POCH}_{2} \mathrm{CH}_{2}\right) ; 1.41\left(\mathrm{~m}, 4 \mathrm{H}, \mathrm{POCH}_{2} \mathrm{CH}_{2} \mathrm{CH}_{2}\right) ; 1.32(\mathrm{~m}, 8 \mathrm{H}$, $\left.\mathrm{POCH}_{2} \mathrm{CH}_{2} \mathrm{CH}_{2} \mathrm{CH}_{2} \mathrm{CH}_{2}\right) .{ }^{13} \mathrm{C}\left\{{ }^{1} \mathrm{H}\right\} \mathrm{NMR} \delta: 67.9\left(\mathrm{~d},{ }^{2} J_{\mathrm{P}-\mathrm{C}}\right.$ $\left.=5.8 \mathrm{~Hz}, \mathrm{POCH}_{2}\right) ; 31.6\left(\mathrm{~d},{ }^{3} J_{\mathrm{P}-\mathrm{C}}=5.8 \mathrm{~Hz}, \mathrm{POCH}_{2} \mathrm{CH}_{2}\right) ; 30.3$ $\left(\mathrm{POCH}_{2} \mathrm{CH}_{2} \mathrm{CH}_{2} \mathrm{CH}_{2}\right) ; 30.6\left(\mathrm{POCH}_{2} \mathrm{CH}_{2} \mathrm{CH}_{2} \mathrm{CH}_{2} \mathrm{CH}_{2}\right)$; $26.7\left(\mathrm{POCH}_{2} \mathrm{CH}_{2} \mathrm{CH}_{2}\right)$. Elementary Analysis $\mathrm{C}_{9} \mathrm{H}_{22} \mathrm{O}_{8} \mathrm{P}_{2}$ calcld C: 33.8; H: 6.9; O: 40.0; P: 19.3 found C: 33.2; H: 7.2; O: 39.9; P: 19.7.

3.8. 1,12-Bis[(dihydroxyphosphinyl)oxy]dodecane (Compound III). $\mathrm{mp}=114^{\circ} \mathrm{C} .{ }^{31} \mathrm{P}\left\{{ }^{1} \mathrm{H}\right\}$ NMR $\delta: 0.9{ }^{1} \mathrm{H}$ NMR $\delta$ : $3.96\left(\mathrm{dt}, 4 \mathrm{H},{ }^{3} J_{\mathrm{H}-\mathrm{H}}={ }^{3} J_{\mathrm{P}-\mathrm{H}}=6.7 \mathrm{~Hz}, \quad \mathrm{POCH}_{2}\right) ; 1.66$ (m, 4H, $\left.\mathrm{POCH}_{2} \mathbf{C H}_{2}\right) ; 1.40\left(\mathrm{~m}, 4 \mathrm{H}, \mathrm{POCH}_{2} \mathrm{CH}_{2} \mathbf{C H}_{2}\right.$ ); $1.32\left(\mathrm{~m}, 12 \mathrm{H}, \quad \mathrm{POCH}_{2} \mathrm{CH}_{2} \mathrm{CH}_{2} \mathbf{C H}_{2} \mathrm{CH}_{2} \mathrm{CH}_{2}\right) .{ }^{13} \mathrm{C}\left\{{ }^{1} \mathrm{H}\right\}$ NMR $\delta: 67.9\left(\mathrm{~d},{ }^{2} J_{\mathrm{P}-\mathrm{C}}=5.8 \mathrm{~Hz}, \mathrm{POCH}_{2}\right) ; 31.6\left(\mathrm{~d},{ }^{3} J_{\mathrm{P}-\mathrm{C}}\right.$ $\left.=5.9 \mathrm{~Hz}, \mathrm{POCH}_{2} \mathrm{CH}_{2}\right) ; 30.4\left(\mathrm{POCH}_{2} \mathrm{CH}_{2} \mathrm{CH}_{2} \mathrm{CH}_{2}\right) ; 30.7$ $\left(\mathrm{POCH}_{2} \mathrm{CH}_{2} \mathrm{CH}_{2} \mathrm{CH}_{2} \mathbf{C H}_{2} \mathrm{CH}_{2}\right) ; 26.3\left(\mathrm{POCH}_{2} \mathrm{CH}_{2} \mathbf{C H}_{2}\right)$. IR $(\mathrm{KBr}),\left(\mathrm{cm}^{-1}\right): 2919,2852,1474(\mathrm{C}-\mathrm{H}), 2360(\mathrm{PO}-\mathrm{H}), 1234$, 1095, $1038(\mathrm{P}=\mathrm{O})$ and $(\mathrm{C}-\mathrm{O}), 1012,937(\mathrm{P}-\mathrm{O}) . M / z\left(\mathrm{MH}^{+}\right)$: 363.25; calcld: 363.13 . Elementary Analysis $\mathrm{C}_{12} \mathrm{H}_{28} \mathrm{O}_{8} \mathrm{P}_{2}$ calcld C: 39.8; H: 7.8; O: 35.3; P: 17.1 found C: 39.7; H: 8.0; O: 35.0; P: 16.9.

\section{Conclusion}

In this work we evaluated three different methodologies to obtain various $\omega$-alkylenediphosphoric acids from condensation of phosphorus oxychloride onto diols with varying chain length. Three methodologies were studied: (i) the conventional heating of both reactants in organic solvent, (ii) the reaction under basic activation at low temperature, and (iii) the use of short microwave heating. After optimization, all methodologies permit obtaining the desired alkylenediphosphoric acids $(\mathrm{HO})_{2}(\mathrm{O}) \mathrm{P}-\mathrm{O}-\left(\mathrm{CH}_{2}\right)_{n}-\mathrm{O}-\mathrm{P}(\mathrm{O})$ $(\mathrm{OH})_{2}$ as main product, but only the microwave assisted one allows for the obtaining of pure products without presence of any traces of polyalkylation byproducts. Moreover, this later methodology permits drastically decreasing the reaction time without using excess of either reactant or any catalyst. It thus appears as an interesting way of synthesizing selectively monoalkylphosphate. In addition, due to relatively friendly conditions, it could be further applied to more sensible substrates.

\section{Conflict of Interests}

The authors declare that there is no conflict of interests regarding the publication of this paper.

\section{References}

[1] D. W. Johnson and J. E. Hils, "Phosphate esters, thiophosphate esters and metal thiophosphates as lubricant additives," Lubricants, vol. 1, no. 4, pp. 132-148, 2013.

[2] M. A. Hegazy, A. S. El-Tabei, A. H. Bedair, and M. A. Sadeq, "An investigation of three novel nonionic surfactants as corrosion inhibitor for carbon steel in $0.5 \mathrm{M} \mathrm{H}_{2} \mathrm{SO}_{4}$," Corrosion Science, vol. 54, no. 1, pp. 219-230, 2012.

[3] D. Ciceri, L. R. Mason, D. J. E. Harvie, J. M. Perera, and G. W. Stevens, "Extraction kinetics of Fe(III) by di-(2-ethylhexyl) phosphoric acid using a Y-Y shaped microfluidic device," Chemical Engineering Research and Design, vol. 92, no. 3, pp. 571-580, 2014. 
[4] R. Murugavel, A. Choudhury, M. G. Walawalkar, R. Pothiraja, and C. N. R. Rao, "Metal complexes of organophosphate esters and open-framework metal phosphates: synthesis, structure, transformations, and applications," Chemical Reviews, vol. 108, no. 9, pp. 3549-3655, 2008.

[5] C. Shi, D. Duan, Y. Jia, and Y. Jing, "A highly efficient solvent system containing ionic liquid in tributyl phosphate for lithium ion extraction," Journal of Molecular Liquids, vol. 200, part B, pp. 191-195, 2014.

[6] C. Shi, Y. Jia, C. Zhang, H. Liu, and Y. Jing, "Extraction of lithium from salt lake brine using room temperature ionic liquid in tributyl phosphate," Fusion Engineering and Design, vol. 90, pp. 1-6, 2015.

[7] S. Raatz and P. Klapper, "Using interfacial tension measurements to analyze the mechanism of zinc extraction with D2EHPA," Hydrometallurgy, vol. 134-135, pp. 19-25, 2013.

[8] A. Cheraghi, M. S. Ardakani, E. Keshavarz Alamdari, D. Haghshenas Fatmesari, D. Darvishi, and S. K. Sadrnezhaad, "Thermodynamics of vanadium $(\mathrm{V})$ solvent extraction by mixture of D2EHPA and TBP," International Journal of Mineral Processing, vol. 138, pp. 49-54, 2015.

[9] D. Das, V. A. Juvekar, V. H. Rupawate, K. Ramprasad, and R. Bhattacharya, "Effect of the nature of organophosphorous acid moiety on co-extraction of $\mathrm{U}(\mathrm{VI})$ and mineral acid from aqueous solutions using $\mathrm{D}_{2}$ EHPA, PC88A and Cyanex 272," Hydrometallurgy, vol. 152, pp. 129-138, 2015.

[10] J. M. Kuiper, R. Hulst, and J. B. F. N. Engberts, "A selective and mild synthetic route to dialkyl phosphates," Synthesis, no. 5, pp. 695-698, 2003.

[11] A. Wagenaar, L. A. M. Rupert, J. B. F. N. Engberts, and D. Hoekstra, "Synthesis and vesicle formation of identical- and mixed-chain di-n-alkyl phosphate amphiphiles," The Journal of Organic Chemistry, vol. 54, no. 11, pp. 2638-2642, 1989.

[12] Q. Taotao, W. Xuechuan, and R. Longfang, "Study on production of lanonol phosphates by a sustained-release method," Journal of Surfactants and Detergents, vol. 10, no. 1, pp. 9-12, 2007.

[13] A. Elias, M. A. Didi, D. Villemin, T. Semaoune, and S. Ouattas, "Synthesis of mono-and dialkylphosphates by the reactions of hydroxycompounds with the phosphorus pentaoxide under microwave irradiation," Phosphorus, Sulfur and Silicon and the Related Elements, vol. 179, no. 12, pp. 2599-2607, 2004.

[14] C. Dueymes, C. Pirat, and R. Pascal, "Facile synthesis of simple mono-alkyl phosphates from phosphoric acid and alcohols," Tetrahedron Letters, vol. 49, no. 36, pp. 5300-5301, 2008.

[15] D. Miller, E.-M. Wiener, A. Turowski, C. Thunig, and H. Hoffmann, "O/W emulsions for cosmetics products stabilized by alkyl phosphates-rheology and storage tests," Colloids and Surfaces A: Physicochemical and Engineering Aspects, vol. 152, no. 1-2, pp. 155-160, 1999.

[16] R. F. Hudson, Structure and Mechanism in Organ-Phosphorus Chemistry, Academic Press, London, UK, 1965.

[17] A. Russo, C. Tonelli, and E. Barchiesi, "New developments in the synthesis and characterization of phosphate esters of linear (per)fluoropolyether monofunctional and difunctional macromonomers," Journal of Polymer Science Part A: Polymer Chemistry, vol. 43, no. 20, pp. 4790-4804, 2005.

[18] Q. Lu, R. P. Ubillas, Y. Zhou et al., "Synthetic analogues of irlbacholine: a novel antifungal plant metabolite isolated from Irlbachia Alata," Journal of Natural Products, vol. 62, no. 6, pp. 824-828, 1999.

[19] L. Perreux and A. Loupy, "A tentative rationalization of microwave effects in organic synthesis according to the reaction medium, and mechanistic considerations", Tetrahedron, vol. 57, no. 45 , pp. 9199-9223, 2001.

[20] C. O. Kappe, "Controlled microwave heating in modern organic synthesis," Angewandte Chemie-International Edition, vol. 43, no. 46, pp. 6250-6284, 2004.

[21] E. Guénin and D. Meziane, "Microwave assisted phosphorus organic chemistry: a review," Current Organic Chemistry, vol. 15, no. 19, pp. 3465-3485, 2011.

[22] G. Keglevich, A. Grün, E. Bálint, N. Z. Kiss, and E. Jablonkai, "Microwave-assisted organophosphorus synthesis," Current Organic Chemistry, vol. 17, no. 5, pp. 545-554, 2013.

[23] M. R. Rosana, Y. Tao, A. E. Stiegman, and G. B. Dudley, "On the rational design of microwave-actuated organic reactions," Chemical Science, vol. 3, no. 4, pp. 1240-1244, 2012. 

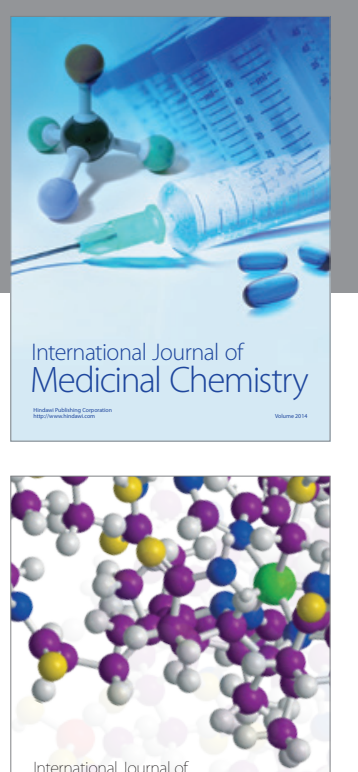

Carbohydrate Chemistry

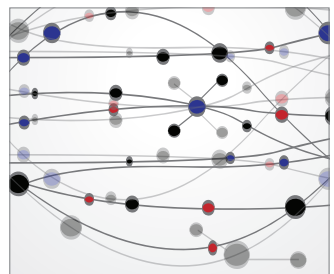

The Scientific World Journal
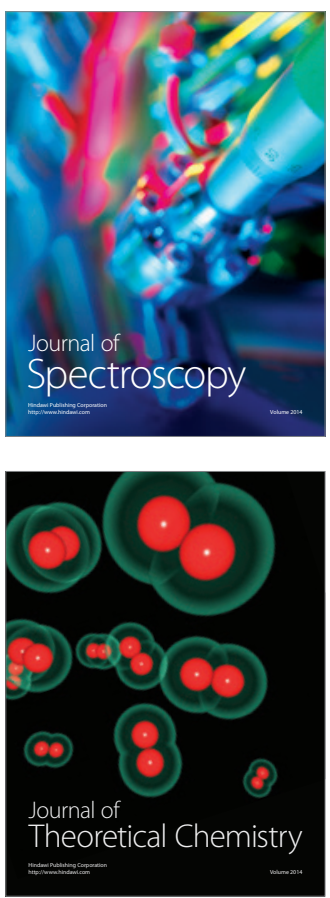
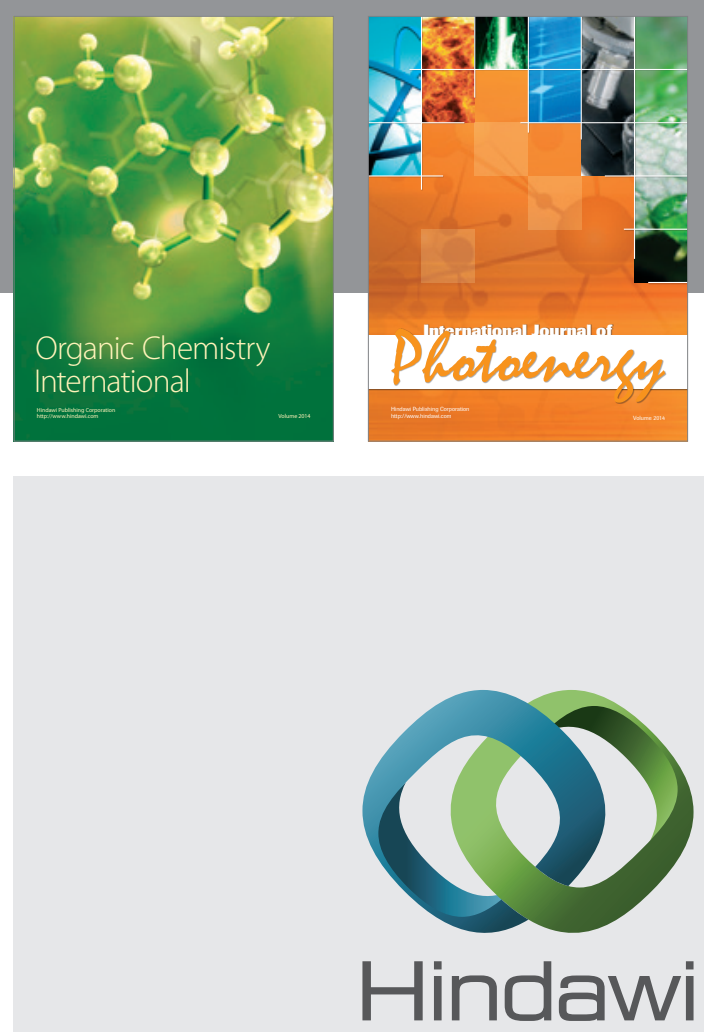

Submit your manuscripts at

http://www.hindawi.com

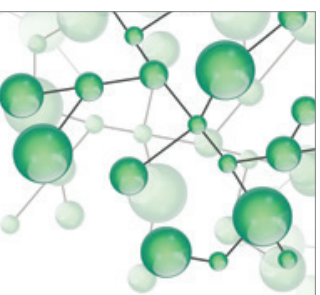

International Journal of

Inorganic Chemistry

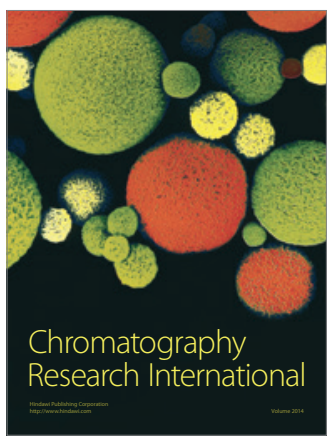

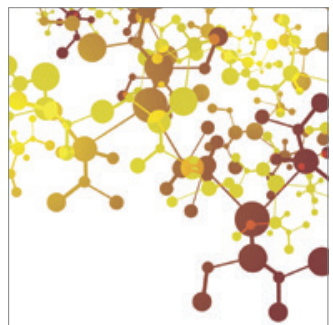

Applied Chemistry
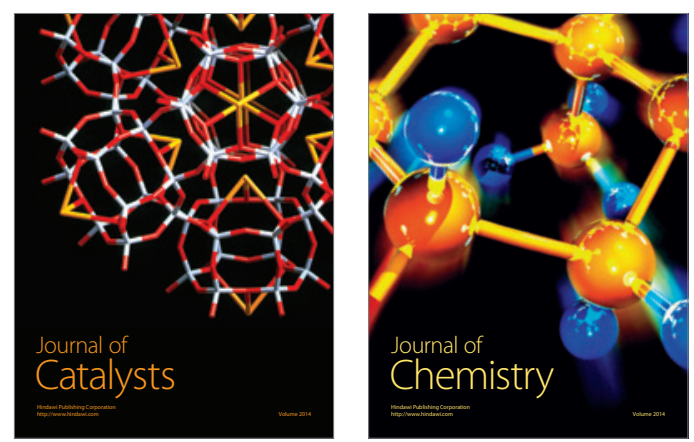
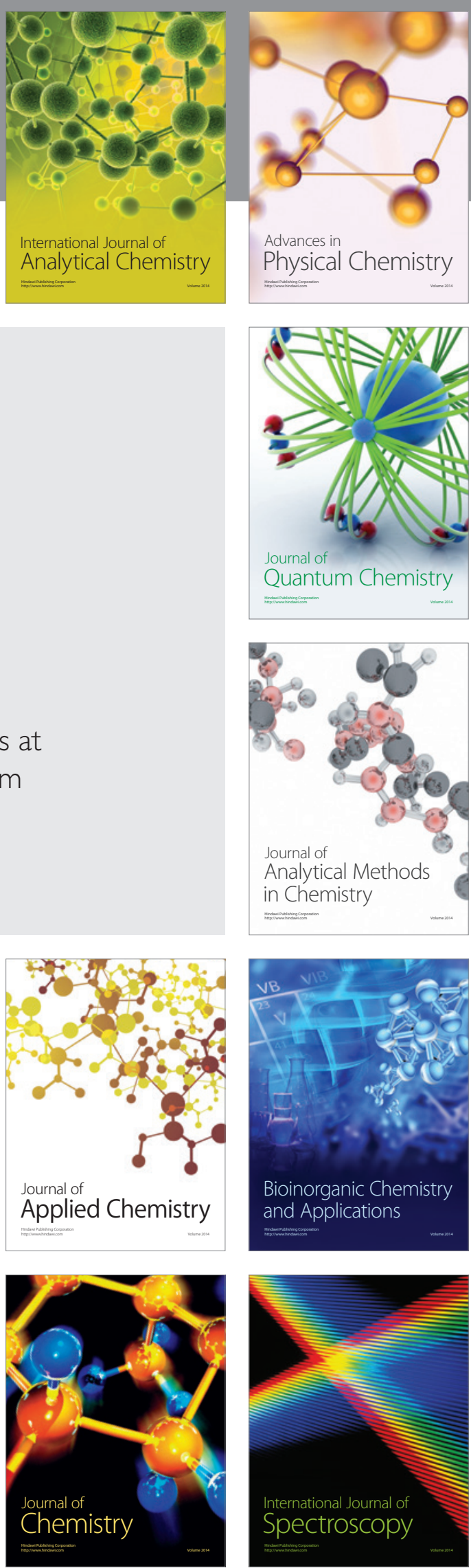